ing. To achieve this the Society will: $(a)$ promote the arranging at regular intervals of international meetings for scientists and engineers working in the field of peaceful application of nuclear energy; (b) promote the circulation of reports and other information of unclassified nature; (c) work for standardization of nomenclature and symbols in nuclear energy ; $(d)$ promote the study of hazard and safety measures arising from the application of nuclear energy; (e) promote publication of nuclear energy works, and possibly encourage the establishment of an international journal in the field; $(f)$ establish a centre of information on availability of nuclear energy materials and equipment. Participation is limited to those nations which have already established nuclear energy projects. The statutes provide, however, that by unanimous decision of the existing members invitations to join the Society may be issued to other European Atomic Energy Commissions which, in the opinion of the Society, have established such projects.

The Society was formally established at a meeting at the Royal Society in London on June 15, at which Sir John D. Cockeroft, director of the Atomic Energy Research Establishment of Britain, was elected president of the Society for the first year. Mr. Gunnar Randers (Norway) was elected executive vice-president, and Dr. Bertrand Goldschmidt (France) vice-president. The Society will be governed by a Council consisting of one delegate from each of the eight member organizations. A working group under the leadership of the executive vice-president will take care of the activities of the Society between. Council meetings. One of the tasks of the working group of the Society is to prepare international conferences on the application of atomic energy. The difference between the recently formed European Atomic Energy Society and the European Nuclear Research Centre in Geneva should be noted. The Geneva establishment will carry out pure scientific research while application of industrial atomic energy is explicitly excluded from its activities. The European Atomic Energy Society is intended as a European forum for promoting the development of industrial uses of atomic energv.

\section{Closing of the Mushroom Research Station, Yaxley, and Transfer of Work}

As a result of the arrangements made between the Mushroom Research Association, Ltd., the Glasshouse Crops Research Institute and the Ministry of Agriculture, the Mushroom Research Station at Yaxley, Peterborough, will close before the end of this year, and mushroom research will be resumed at the new Glasshouse Crops Research Institute, Littlehampton, as soon as suitable buildings and equipment are ready. Of the staff at Yaxley, Mr. P. B. Flegg, Miss D. G. Gandy and Miss I. I. Warman will join the new Institute in due course. The director of research, Dr. R. L. Edwards, will remain at Yaxley until November 30 to complete the cropping experiments now in progress and to prepare a final report; after that he will transfer to commercial mushroom-growing and practise as a private consultant. After the closing of the Station, communications concerning the research programme should be addressed to Dr. W. F. Bewley, director of the Glasshouse Crops Research Institute, at first in Cheshunt, Herts, and later at the new buildings in Littlehampton, Sussex. Requests for advice, examination of samples, etc., should be sent to the nearest horticultural officer of the National Agricultural Advisory Service, who will forward them to his regional laboratory or to the Research Institute if necessary. Information concerning international conferences on mushroom science can be obtained from Dr. R. L. Edwærds, at Rateliffe Lodge, South Luffenham, Oakham, Rutland.

\section{Meteoritics: a New Journal}

From the time of the inception of the Meteoritical Society in 1933, its Notes and Contributions were published regularly in the monthly magazine, Popular Astronomy, until December 1951, when that periodical was discontinued. By arrangement of the Council of the Society with the University of New Mexico, a new publication entitled Meteoritics : The Journal of the Meteoritical Society and the Institute of Meteoritics of the University of New Mexico has been established. The first number, consisting of an introduction and twenty-three articles, appeared in December last year and serves as a complete issue for 1953 (pp. 123 ; obtainable from the Secretary of the Meteoritical Society, Dr. John A. Russell, Department of Astronomy, University of Southern California, Los Angeles 7, Cal.; 4 dollars a year). Meteoritics is concerned with the investigation of the matter that reaches us from space beyond the earth. Prof. F. C. Leonard discusses its recent progress and future development in a paper which includes an address delivered at the opening of the new Institute of Meteoritics - the only establishment of its kind in the world-and a list of some fifty problems awaiting solution or requiring further research. In response to a questionnaire as to the contributions and problems thought to be most important, Prof. Harrison Brown states his conviction that study of trace elements and isotope fractionation will indicate the conditions under which meteorites were formed; and Dr. F. L. Whipple lists among his major contributions the absence of hyperbolic meteorites and the recognition of planetoidal and cometary types. The articles cover a wide range of interests, one of the most notable being a systematic study of the formation of craters by high-speed particles. The new journal, which is attractively printed and illustrated, is expected eventually to become a quarterly. The editors and other officers of both the Society and the Institute are to be congratulated on an initial success which augurs well for the future of their enterprise.

\section{The Starfish}

No. 7 of The Starfish, the journal of the Association of School Natural History Societies, has recently been published (obtainable from G. I. Crawford, 18 East Drive, Carshalton, Surrey. 2s. to nonmembers). The journal is edited by G. I. Crawford, Major Maxwell Knight and R. S. R. Fitter. It opens with a report of the annual general meeting of the Association and an account of the exhibition held on November 7 at the British Museum (Natural History). John Ounsted describes the Botanical Society of the British Isles, stressing the facilities it offers to juveniles. R. H. Winterbottom (Dulwich College) records a winter census of gulls. Michael L. Elliott (West Buckland School) gives a fascinating and revealing account of how he keeps and studies adders in captivity. Patricia Brown (Orange Hill Girls Grammar School) describes how trout are kept at her school. Christopher N. G. Sell (Bishop's Stortford College) and some collcagues have been making 